\title{
Symbiosis Problemsin Codependent Families
}

\author{
Ekaterina Raklova \\ Candidate of Psychological Science, Innovative University of Eurasia, Pavlodar city \\ *Corresponding Author: katie777@mail.ru
}

Copyright $@ 2013$ Horizon Research Publishing All rights reserved.

\begin{abstract}
The means for correction of codependent individual states problem is considered in this articleWe believe that codependency is a dynamic form, so that it can be corrected. The level of codependent states of the individual may be reduced under the certain conditions. The article studies codependency as a condition that occurs in family members of alcoholics or people with other forms of addiction, which is often worse than the disease itself. Codependency can be compared to a symbiosis of an alcoholic and his/her family members, but this combination has a destructive tendency, not only for the "donor", but for all family members. Codependency is originally formed by humanitarian reasons, such as helping a drinker, but with the development of alcoholism the mechanism of codependency obtains the reverse vector. Experts' fear is caused especially by the pattern of learned behaviors, feelings, and beliefs that make life troubled, effect adversely on people's adaptation and lead to negative personality changes, problems of harmonious and comprehensive development. This defines codependency as a serious psychological, medical, educational and social problem.
\end{abstract}

Keywords Psychological Birth, State of Codependency, The Symptoms of Codependency, Addiction, Adaptation, Physical Health, Persecutor, Rescuer, Victim

\section{Introduction}

The means for correction of codependent individual states problem still remains under-developed in psychology. The question of diagnostic factors, levels of codependency is unsolved. Psychological correction of codependency greatly enhances the adaptive capacity of codependency personality, provides activity of the individual in the activity, the acquisition of communicative skills.Modern society is characterized by crises in many spheres of public life Alcoholism has become a social problem and poses a real threat to the national security of the country.

Psycho-pedagogical science is an urgent need to develop a conceptual directions, practical recommendations for comprehensive psycho-pedagogical impact on the identity of co-dependent women, which determines the relevance of a detailed study of codependency .

In recent decades, the modern sciences of psychology, sociology, pedagogy and medicine pay more and more attention to codependency, as one of the currently important problems of modern anthropology. Many researchers point to the exceptional importance of this phenomenon in the life of individuals and certain social groups. V.D. Moskalenko (1995), the author of a fundamental study on the codependency, says that the problem of individual codependency state takes a special place in the modern scientific knowledge. This psychological phenomenon is recognized, as "the central problem of modern civilization" (E. Smit, 1991; V. Satir, 2000; G. Klaud, 1999; E. Erikson, 1950; N. Ivanets, I. Vachkov, M. Bitti, A. Myager, E. Eydemiller, A. Zakharov.) and the most important issue of our time is the release of an individual from the state of codependency.

Symbiosis in families is sometimes difficult to recognize as a serious problem, because it supports the illusion "We are one big happy family." There was a time, when this form of relationship was considered as a healthy one. As soon as we become aware of an important need in the psychological birth and personal independency, the symbiosis is perceived as a form of dysfunctional relationship. [1]

Symbiosis can be expressed, for example, in the hope that a son will be called a graduate student or that he will continue the family tradition and become a doctor or a sportsman. Other subjects of "legacy", such as a life not far from the family home, a certain number of children in the family or marriage with a certain husband / wife are virtually the same forms of symbiosis. Such life decisions themselves are not negative. The problem is in the absence of a conscious personal choice of an individual concerned and a significant number of external expectations, because such restrictions prevent the development of the true "I". Symbiotic dynamics are also generally insufficiently understood; this means that people who are involved are hardly aware that they act in accordance with someone's expectations [3.4].

Each family system has its own internal dynamics. A healthy system is based on the division of responsibilities and tasks in the family (no one exploited by anyone). In a healthy system, all the elements are associated with each other by two-way communication. In contrast to the 
dysfunctional system, which is usually closed, healthy system is open. This means that two-way communication system connects a family with greater social system and the family is a part of it.

Systems theory applied to family facilitates recognition of conflicts and difficulties that make harmonious co-existence and the individual development of each family member impossible. Changes in the operation of any single element causes a change in the functioning of the entire system and may lead to a worsening of interpersonal relations in the family. [4]

According to E. Woydytto (1997), people in America rarely rely on someone when they try to solve their problems. The wives of alcoholics are not an exception, and long before V. Satir, they came up with the idea that they should protect the welfare of their unhealthy families.

Stories of parents, who direct their children to act only as smart students or promising athletes, illustrate the need of unhealthy adults to be evaluated by the success of their children. Children, who depend on parents with exaggerated needs in fame and glory, often become empty dependent adults and feel that they will never achieve a considerable success. Regardless of their achievements, they often suffer from low self - esteem and poor self-image and feel like failures. [5]

Typically, a feeling of breathlessness motivates an individual to get out of this confusion. People may feel as if they are dying, sick or unwell, which causes the fear of death. Only then they begin their attempts to break out of this system.

In the symbiotic family, personal boundaries between family members do not actually exist. In many codependent families, where the parents are very symbiotic, children and adults can even switch their roles. It is very typical for alcoholic families, where children have to go shopping, to wash and put their drunken parents in bed. Adults can also play roles of children to get education, love, affection and comfort that in fact parents should give instead of receiving. It creates an atmosphere, where incest or sexual abuses are possible, that explains the prevalence of such abnormalities in alcoholic families [5.6].

\section{Materials and Methods}

Elton Joseph Pearce $(1977,1985)$ considered bonding as the central issue of early childhood development and studied the circumstances that prevent the formation of bonds, as well as the influence of bonds or their absence on education and the establishment of relations. He identified five steps / elements for creation of a good bonding in the relationship mother / child in the first few hours, days, and months after the birth of the child:

1) nursing and holding a child in mother's or father's arms (the best contact is skin to skin);

2) long and quiet eye contact with a child;

3) smiling to a child;
4) singing lullaby;

5) stimulation of a child with strokes and massage.

Pierce (1985) identified eight stages of bonding and considered the development of a person as a consequence of bonds that keep the process of life in the same way. He described it as an instinct, which directs people toward the full development of spiritual abilities. Stages of bonding by the Pierce are the following:

1) with mother (at birth and immediately after it);

2) with father and family (immediately after birth);

3) with the Earth (at the age of about four years);

4) with the society (at the age of seven years);

5) with the main part of the society knowledge (starting from eleven years);

6) with a person of the opposite sex (at puberty);

7) with a child (as a parent);

8) spiritual liaison.

The first seven steps together comprise the eighth, which Peirce calls "spiritual liaison", and if this process is completed, the person becomes able to feel connected to the world and to everyone in this world.

Similar to any development process, it is possible to return to the point, at which the process has been broken, and restore it. The breakage of bonds in early childhood can be healed with the help of fixed relationships, psychotherapy, support groups and individual work. Broken bond with the Earth can also be restored, but we know little about it. Usual methods of returning to nature in Native American traditions include such activities as gardening, planting trees and flowers.

Healthy bonding in schools is supported by joint actions that recognize the uniqueness of an individual and encourage acceptable physical contact such as hugging, "dog pile" (where all children randomly lie on the floor like newborn pups in the nest), circle dance or movement of children through tight helix that is formed from aligned rows of people. These activities must be started with information and discussion of what is acceptable and unacceptable touching, as well as strong support in setting individual limits and boundaries on touching and close body contact. Teachers should speak openly about it and support the desirable and acceptable behavior. This behavior and encouraging atmosphere created by the teacher will help children to learn to distinguish healthy bonding (which encourages existence of individual needs and boundaries) from unhealthy ones that are typical for symbiosis (which interfere the free choice, transfer external expectations and deny the boundaries and limitations) [7.8 ].

Recent studies (Magid and McKelvey, 1988) consider the bad bond in the age from birth to two years as the main cause of antisocial personality disorders (APD). People with such disorders (about $15 \%$ of the adult U.S. population) have a combination of ugly traits. They are arrogant, shameless, immoral, impulsive, uncommunicative, shallow-brained, heartless, irresponsible, disrespectful, treacherous and deceitful. Perhaps, these people will not kill, but they will be willing to lie, cheat and steal without any shame. Some 
extreme examples can be found among prisoners, for example, Charles Manson, and in psychiatric clinics, but a lot of people with less severe symptoms exist in all social layers.

Scientific studies show that now there are more people with APD in society than ever before. The growing number of bad bonding that contributes to the formation of APD is attributed to the following cultural trends:

1) increased number of pregnancies among adolescents;

2) increased number of inexperienced teenage mothers who bring up their children;

3) increased number of divorces;

4) increase in cases of child abuse;

5) large number of adoptions;

6) increased number of sending children to raise in a foster home;

7) insufficient daily care of children.

Studies also show that interruption in the process of bonding, such as hospitalization, sickness of parents and their absence, has a significant effect on children. It has a particularly negative effect on a child at birth and during the separation stage from nine months to three years.

Magid and McKelvey consider the main cause of APD in the United States is that teenagers become parents. Teenage mothers are still children themselves and do not know how to properly interact with their infants. The second important reason of the high level of APD is insufficient daily care of children. Most of day-care nannies receive little payment for their work and are not professional enough for their duties. There is a high turnover rate among nannies and many of them are almost children themselves. Child care is performed at a level that is below any standards.

Another characteristic of dysfunctional families is that the imbalanced system tends to get back to its original state. The wives and children of alcoholics do not take them seriously and do not listen to their opinion. Such a bad treatment of loving people in relation to the alcoholic, who begins to sober, can easily weaken his motivation. Then everything goes back to how it was: the alcoholic starts drinking, feeling of guilt and the worsening of disease again prevent him from playing his role of an equal partner and educator of his children in the family. Family gets stuck more and more in the mire of unhealthy habits that occur as a result of feelings of loneliness, lack of mutual trust and discrepancies between what they can recognize, as well as between what they do and say $[9,10]$.

The verbal and non-verbal means of psychological correction codependent individual states in training groups that reduce the level of codependency was determined. The analysis of the psychological conditions of codependency (patterns of learned behaviors, poor health, adjustment disorders, addiction to obsessive concern in the relationship). It was found that codependency is the trigger pathological personality development.The conceptual framework corrective treatment to overcome codependency was developed.The efficaciancy of psychological treatment of codependency verbal ("Family Photo", "Sociodrama" socio-psychological training) and non-verbal means of correction ("Family sculpture", "Family choreography," "Role Card Game" technology).

\section{Results}

In a study of the influence of verbal means of co-dependent on the dynamics of the individual states in the early intervention program subjects were asked a series of questions from our specially developed questionnaire.

- What is your role in paternal home?

- Did you fell yourself oppressed?

- What did you feel for your husband when married?

- What in your opinion the husband was expecting from you in marriage?

- What do you expect from your husband for you personally?

- From what sources did you get your base for your self-evaluation?

- What do you do for yourself in order to reveal your own abilities?

- Does your health depend on entirely on external circumstances?

Reflection and discussion of these issues helps to understand that alcoholism is a disease with a very serious and affects the whole family.

A list of topics that we offer to the panel discussions on overcoming codependency is reflected in the guidance manual for the co-dependent wives.

The manual includes information on the following issues: (work with the senses, controlling behavior, exclusion, the action-reaction, borders, parental family, self-esteem, getting rid of the psychology of the victim, yes, we know how to think, the ability to "bury" their losses, set their own goals, the statement itself, "I have the right").

In the social - psychological training for group discussion, role play, verbal signals ego states to (Eric Berne), family photo, etc. was apllied.

Studies were carried out by us in the following way:

Stage 1 - warming-up, includes a series of games, exercises that set up the test to practice, create a positive, friendly attitude towards each other, the situation and the coach (10-15 min).

Stage 2 - psychological exercises, assignments, performed individually, in pairs, in small groups, in al of the training group (50-60 min.).Exercises divided into specific groups: technology interaction; verbal and nonverbal communication, and special exercises aimed at reducing the state codependent person.

Stage 3 - a reflection of its states and an analysis of the behavioral activity of training participants (10-15 min.).

To study the effect of socio-psychological training to the level of co-dependent conditions of the person we have organized the re-examination of codependent.

As an additional diagnostic method we have used survey respondents in all age groups of experimental. The 
questionnaire was applied methods of scaling. Subjects were asked to rank five of the eight proposed of factors which have influenced the decline in co-dependent states of the individual. The question was: "What has helped you get rid of difficulties communicating with your alcohol addicted husband?

As the responses subjects noted: awareness of their own problems, identifying their state of codependency, seeking help for themselves, the appearance of desire to change, reduction of fear, freedom from guilt, spiritual re-evaluation, etc.

In the table (1), figure (1) the results of the survey of women are summarized.

In general, the groups of examined codependent women characterized by the following:

- Unstable self-esteem, low self-esteem;

- Failure to plan for the immediate and long-term goals;

- Occasional uprising of social functioning;

- Pessimisstic personal attitude;

- Absence of alternative system of values.

Using the arithmetic mean, the degree of preference for each of the factorswas identified. The received data is on the chart as follows:

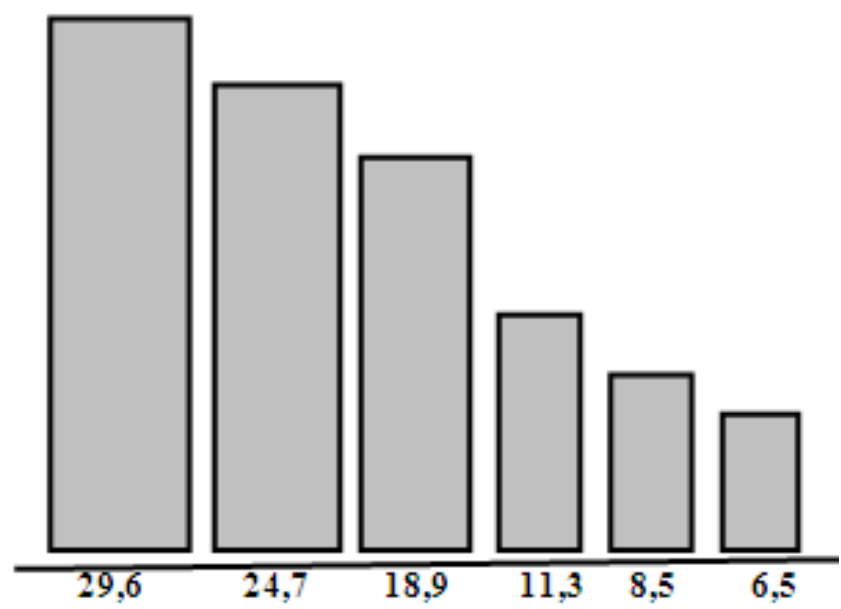

Figure 1. Distribution of factors affecting on the decline of codependency

Note:

1 - social-psychological training;

2 - family imagery, family choregraphy.

3 -work with verbal and non-verbal cues emanating from the ego-states

(swinish parent, a caring parent, an adult, a little professor, a truel child), family portarait;

4 -sociodrama (transactional discussion)

5 -role card play;

6 -interest clubs.

As we can see from the chart the social-psychological training, family imagery, family choreography is marked with codependent women as advantageous in reducing the level of codependent states of the individual.It should be noted that in the third place with a slight divergence is another factor that influenced this process is working with verbal and non-verbal cues emanating from the ego states and the family portrait. It can be concluded that means under consideration can be effective when a system approach is used.

Table 1. The quantitative and qualitative selection factors influencing the decline in the state of codependency personality. Experimental group. $\mathrm{N}=92$

\begin{tabular}{|c|c|c|c|c|}
\hline Factor & Choice 1 & Choice2 & Choice 3 & $\begin{array}{c}\text { Amount of } \\
\text { choices }\end{array}$ \\
\hline Factor 1 & 29 & 26 & 26 & 81 \\
\hline Factor 2 & 23 & 24 & 19 & 66 \\
\hline Factor 3 & 16 & 16 & 24 & 56 \\
\hline Factor 4 & 9 & 10 & 12 & 31 \\
\hline Factor 5 & 10 & 7 & 6 & 23 \\
\hline Factor 6 & 5 & 9 & 5 & 19 \\
\hline Total & 92 & 92 & 92 & 276 \\
\hline
\end{tabular}

Once you realize your codependency, and acknowledge that it makes your life difficult, if not miserable, you do the most important thing. From here the way of recovery becomes more clear (though not always easier), because now you see everything much more clear. At this stage, participation in the "12 steps" programs or support groups is almost necessary. There you will find team-mates with similar ideas that will help to support your point of view, if you experience hesitation.

Alcoholism is, of course, a disease that is completely democratic and does not choose its victims. [11,15,17]

Creating a new sphere of study about the systemic treatment of addictions that takes into consideration all family members was later made possible mainly by professionals, who were the first to overcome their own false shame, guilt and rejection [12,19].

Codependency is important in the study of individual characteristics of a person. The problem of codependency is one of the most complex and actively studied. This is due to the exceptional role of codependency in the formation of uniqueness of an individual, its role in the interaction of a person with the world and close relation with his mental and physical health.

Thus, the phenomenon of codependency requires further analysis and systematization of approaches to the study of codependency state of an individual.

\section{Discussion}

In recent decades, the modern family in most countries, is undergoing a major change: the fall of the birth rate, the increasing complexity of interpersonal relationships, the increase in divorces, the increase in single-parent families and families with step-parents, the prevalence of non-marital births. In our country the acute social problems of the family is the reduction of its material level, the deterioration of physical and mental health of children and their parents, an increase of older single men and women.

Satir V. (1992) considers the family as a microcosmos of 
the world. «lit is enough to know the family to understand it.The demonstration of power, intimacy, independence, confidence, communication skills, existing in it is the key to unlock many of life. If we want to change the world, we should change the family $»$.

The codependency state of a person affects all areas of the psyche: the affective-emotional, communicative, moral and volitional, cognitive, behavioral. Special features in this case is the development of motivation, self-awareness and self-esteem. The studies of Beattii M. , Satir, V.V. , Lebedinskiy, SpivakovskayaA.S. , Garbuzova V.I, Breslau G.M., Kagan V.E., KucherovE.V., Jakubovsky M.L., Moskalenko V.D., Dmitrieva N.V. allow to conclude that people with codependency state of the individual are at risk for neurosis, addictive behavior, emotional personality disorders.

The interest of psychologists to the problem of co-dependence is mediated primarily by the fact that co-dependency is a major risk factor for the development of many psychosomatic deviations (Satir V., Smith A.W., Dmitriev N, Moskalenko V.), neuropsychiatric diseases (Kikolov A.I., Plotnikov V.V.), neurotic disorders (Freud, Horney K.)

In psychology, the selection of codependency state of the individual as a separate phenomenon is connected with the fact that it takes one of the leading places in the overall picture of mental and emotional disorders, and a source of social disadaptation ( Dubrovin I.V., Zakharov A., Kotchoubey B.I., Kislovskaya V.R.).

Nearly all experts, somehow relevant to the study of co-dependency grant the a significant impact of codependency on the effectiveness of the individual states and the quality of the individual, emotional state, self-esteem, adaptation, physical health.

\section{REFERENCES}

[1] Arguelles, Jose. 1987. The May an Factor. Santa Fe: Bear \& Co.

[2] Beattie, Melody. 1987. Co-dependent No More. New York: Harper \& Row.

[3] Beattie M. The alcoholic in the family, or to overcome codependency. M., 1997.

[4] Black, Claudia. 1981. It Wil Never Happen to Me. Denver, CO: M.A.C. Printing and Publication Division.

[5] Cloud, G., J. When Taundsen say YES. When to say NO. Spb., 1999.

[6] Fingarette, Herbert. 1988. Heavy Drinking: The Myth of Alcoholism as a Disease. Berkeley, CA: University of California Press.

[7] Griffin, Susan. 1978. Woman and Nature. New York: Harper \& Row.

[8] Halpern, Howard. 1982. How To Break Your Addiction To A Person. New York: McGraw-Hil Book Company.

[9] Kaplan, Louise J. 1978. Oneness and Separateness: From Infant to Individual. New York: Simon and Schuster.

[10] Karpman, Steven. 1968. "Fairytales and Script Drama Analysis", Transitiona Analysis Bulletin. 7:39-43.

[11] Korolenko cs, DmitrievaN.V.Sotsiometricheskaya psychiatry. - New York: Academic Project, Yekaterinburg: Business Book, 2000.

[12] Korolenko TS.P., Dmitrieva NV, Zagoruiko EN Identity. Novosibirsk, 2007. 472s.

[13] Moskalenko.V.D. The social work with families of alcoholics. Moscow, 1992.

[14] Miroshnichenko, LD Addiction encyclopedia in two parts. M., 2001.

[15] Miller, Alice. 1983. For Your Own Good. New York: Farrar, Straus, Giroux.

[16] Schiff, Jacqui, et al. 1975. The Cathexis Reader. New York: Harper \& Row.

[17] Subby, Robert. 1984. "Inside the Chemically Dependent Marriage: Denia Manipulation”, in Co-Dependency: An Emerging Issue. Pompano Beach, FL: Health Communications. Arguelles, Jose. 1987. The May an Factor. Santa Fe: Bear \& Co.

[18] Schaef, Anne Wilson. 1986. Co-Dependence Misunderstood-Mistreated. New York: Harper \& Row.

[19] Schiff, Jacqui, et al. 1975. The Cathexis Reader. New York: Harper \& Row.

[20] Young E Co alcoholism as a disease implications for psychotherapy / / J Psychoactive Drugs - 987-Vol 19 N3-P 257268. 